\title{
UMA POLITICA PARA A EDUCAÇĀO SUPERIOR
}

José Goldemberg(1)

RESUMO: Impõe-se a formulação de uma politica explicita para a educação superior, capaz de enfrentar a atual turbulência das universidades brasileiras. A tendência corporativista de professores, funcionários civis $e$ estudantes, como resposta ao sistema de rigido controle federal, levaram a uma situação na qual os objetivos da educação superior obscureceram-se. Propde-se o retorno a uma Universidade orientada para o bem público, para a alta qualidade da produção cientifica e tecnológica e para a diversificação da sua atividade, inclusive para atender as necessidades regionais.
ABSTRACT: A strong case is made for the formulation of an explicit policy for higher education capable of facing the present turmoil in Brazilian universities. Rampant corporativism of professors, civil servants and students as a response to a rigid system of federal control has led to a situation in which the basic objectives of higher education have been lost. The return to an University oriented towards the public good, higher quality of the scientific and technological production and a diversification of the type of university according to regional and/or other needs is proposed.

As universidades brasileiras têm sido recentemente objeto de um severo escrutínio pelos jornais e pela televisão. Assim, enquanto a comunidade acadêmica discute a questão da avaliação, a imprensa se adianta e realiza uma avaliação própria, que oferece ao público.

O problema está em que a tendência da imprensa é acentuar quase que exclusivamente os aspectos negativos. As próprias declarações dos entrevistados são selecionadas e filtradas, oferecendo uma falsa impressão de unanimidade nos ataques e nas críticas. A goteira de um prédio pode merecer maior cobertura do que o resultado inovador de uma pesquisa que mobilizou, durante anos, toda uma equipe de investigadores.

E necessário e urgente uma apresentação mais objetiva do que vem ocorrendo com a educação superior, dissipando o pessimismo que cerca essa área e evitando os riscos de uma desmoralização permanente, que seria certamente injusta.

Vejamos, portanto, quais as dificuldades reais que as universida-

(1) Reitor da Universidade de São Paulo. 
des enfrentam e a contribuição que efetivamente têm dado para o desenvolvimento científico, econômico, social e cultural do País.

As universidades brasileiras surgiram apenas na década de 30 . São, portanto, muito jovens. Até o século $X \mid X$, a metrópole portuguesa e o governo imperial não as acharam necessárias, limitando-se a criar escolas profissionais como as de Direito, Medicina, Engenharia e Minas.

Foi o grande surto de modernização do início do século, associado à industrialização, à imigração européia e à urbanização, que provocou uma nova concepção de educação e levou a profundas reformas do ensino em todos os níveis. A criação das universidades se insere assim numa transformação global da sociedade e do sistema educacional.

No Paraná, no Rio Grande do Sul, em Minas Gerais, no Rio de Janeiro e em São Paulo, os intelectuais e os setores das classes dominantes integrados nesse processo de transformação social, propuseram a criação de universidades como parte integrante do projeto modernizante. A criação da USP foi, talvez, o exemplo mais bem-sucedido desse tipo de iniciativa.

A maioria das novas universidades foi criada, portanto, como resposta a desafios locais e assumiu formas diferentes em cada região. Mas, ao mesmo tempo em que essas iniciativas começavam a dar frutos, a vitória da revolução de $\mathbf{3 0}$ iniciava uma política centralizadora que alterou profundamente o panorama do ensino superior brasileiro. Menos que criar universidades, o que o Governo Federal se propôs foi regulamentar minuciosamente como elas deveriam ser, iniciando o processo de controle do ensino universitário pelo recém-criado Ministério da Educação.

Impôs-se assim, a todo o Brasil, um modelo único e rígido de universidade, tendência essa que o Estado Novo só veio a fortalecer. As iniciativas locais tiveram que se adaptar ao leito de Procusto da legislação federal, e o Governo Central, controlando todo o ensino, limitou-se a criar uma única universidade: a do Brasil.

O período democrático que se seguiu ao Estado Novo não abateu o centralismo anterior. Ao contrário, acabou por ampliá-lo, pois os Estados passaram a reivindicar que a União se responsabilizasse pela manutenção das universidades criadas pelas iniciativas locais. Estabeleceu-se, assim, um vasto sistema de universidades federais, conce- 
bidas todas no mesmo molde, dentro do melhor estilo napoleônico que é tão caro à nossa tradição política. A ampliação do sistema implicou a multiplicação dos controles burocráticos, sufocando a capacidade de adaptação e evolução das próprias universidades. Criou também uma tradição de total dependência em relação ao Governo Federal, ao qual se atribuem todas as culpas, e do qual se exigem todas as soluções, num mecanismo perverso que só faz fortalecer o centralismo autoritário.

A reforma de 68, embora tivesse alterado profundamente a estrutura interna da universidade, não modificou a subordinação do sistema ao Ministério da Educação. Aliás, isso seria mesmo contraditório com a revitalização das tendências centralizadoras do regime autoritário.

A combinação de centralismo e autoritarismo certamente dificultou o encaminhamento de soluções para os grandes problemas que as universidades brasileiras tiveram que enfrentar nas décadas de $60 \mathrm{e}$ 70: a necessidade de ampliar o acesso ao ensino superior e responder ao desafio de uma universidade de massas. A transformação necessária para responder às demandas crescentes de uma sociedade em mudança não se colocava como um problema exclusivamente brasileiro. No mundo todo, o movimento estudantil de 1968 deu início a um processo de profunda reformulação do sistema de ensino superior, que resultou em sua ampliação e diferenciação interna.

No Brasil, o atendimento das novas demandas se processou através da manutenção de um modelo único de universidade e, sem que se fizessem os investimentos necessários para a formação dos recursos humanos e a instalação de uma infra-estrutura material adequada, acabou-se por sacrificar a qualidade pela quantidade. A insuficiência e a má aplicação dos recursos públicos, por outro lado, estimularam o crescimento dos estabelecimentos particulares, cuja qualidade jamais foi suficientemente controlada. Dessa forma, a universidade brasileira, que sempre tivera dificuldades em implantar a pesquisa, renovar o ensino e elevar ó nível de qualificação do pessoal docente, viu seus problemas multiplicados.

Apesar de tudo isso, forçoso é reconhecer que as universidades brasileiras, enfrentando todas essas dificuldades, realizaram tarefas importantes. Se bem que a qualidade média dos cursos deixa muito a desejar, as universidades conseguiram formar mão-de-obra razoavelmente qualificada, e, inclusive, uma parcela relativamente pequena, 
mas altamente significativa, de profissionais, técnicos e cientistas de altíssimo nível. A pesquisa não se generalizou como parte integrante da vida acadêmica, mas os núcleos de pesquisa já existéntes-se preservaram e muitos outros se constituíram. A produção científica do conjunto dos docentes é, em média, muito pequena, mas não há como negar que o País conta hoje com uma produção científica competitiva ao nível internacional, que é muito maior do que a do passado. A qualificação do pessoal docente é ainda muito baixa, mas as universidades contam com um número crescente de mestres e doutores que receberam treinamento adequado e são capazes de oferecer um ensino de melhor qualidade e realizar pesquisas competentes.

As universidades são, ainda, instituições pouco flexíveis. Mas a atuação da CAPES na pós-graduação, da FINEP do CNPq e da FAPESP no financiamento de pesquisas e de todas elas na concessão de bolsas, abriu canais para o desenvolvimento científico que foram amplamente utilizados pelas universidades.

É verdade que tudo isso indica as deficiências do ensino superior brasileiro. Mas não se justifica uma atitude totalmente pessimista em relação às nossas universidades, muitas das quais são excelentes. Entre essas, não há como não incluir a USP

Há ainda a considerar um outro lado desse processo, que diz respeito à alteração do panorama político dentro das próprias universidades.

A oposição ao regime político autoritário dentro de um sistema altamente centralizado acabou por favorecer a organização de movimentos corporativos: inicialmente, de professores e depois, também de funcionários. Com a liberalização do regime, durante o longo processo de transição, esses movimentos se fortaleceram, pois se constituíram como os únicos instrumentos de luta pela democratização interna da universidade, e pela melhoria das condições de trabalho e de remuneração dos docentes e funcionários.

Esses movimentos, em enfrentamentos sucessivos com o poder Executivo, lograram vitórias expressivas, tanto na liberalização interna das universidades, quanto na obtenção de vantagens salariais e de carreira. Foi em grande parte em função desses movimentos, que nos encontramos hoje, finalmente, numa situação em que o salário dos docentes universitários está, em muitos casos, acima da média do mercado de trabalho. Por outro lado, as verbas de custeio não decresceram em números absolutos, embora o próprio aumento da folha de 
pagamento de pessoal tenha provocado uma diminuição relativa. Mas. há expectativas fundadas de que esses recursos venham a crescer.

Temos assim, hoje, condições para realizar uma verdadeira reforma da universidade, transformando-a naquilo que ela almeja ser:

um centro de produção de conhecimento relevante e de formação de pessoal qualificado para as tarefas de desenvolvimento do País.

Mas, para isso, é necessário formular uma política clara para o ensino superior brasileiro.

Sem essa formulação política, o corporativismo dos professores e funcionários os levará a exigir sempre mais, sem perceber que já são um grupo altamente privilegiado no funcionalismo público, e que essa situação não pode se prolongar indefinidamente.

É necessário lembrar também que, se o movimento docente conseguiu ganhos expressivos em termos de níveis salariais, mostrou-se singularmente incapaz, em que pese a retórica das assembléias, de mobilizar professores para melhorar a qualidade do ensino ou promover o desenvolvimento da pesquisa. Mas as greves salariais, tendo garantido vantagens significativas no passado, transformaram-se em instrumento privilegiado de luta.

Universidades não são fábricas onde os operários em greve deixam de receber seus salários e precisam, por isso, estar altamente mobilizados para enfrentar os patrões. Nas greves universitárias não há custos nem riscos para os grevistas, sejam eles professores, funcionários, ou alunos. Por isso, multiplicam-se facilmente e a universidade, de greve em greve, se paralisa e se desmoraliza.

Ao contrário do que ocorre nas greves operárias, nas da universidade os prejuízos para a sociedade se verificam apenas a médio e longo prazos. Por essa razão, as demandas não são atendidas em função da pressão decorrente de prejuízos econômicos imediatos e o enfrentamento não se trava nos locais de trabalho, mas nas páginas dos jornais. A luta consiste em conseguir as simpatias da opinião pública e construir uma pressão política sobre os setores da administração responsáveis pelo atendimento das demandas. Sem uma política para o ensino superior, os órgãos governamentais decidem não em função do mérito das reivindicações e dos seus efeitos sobre o sistema de ensino, mas em função dos interesses políticos do momento, e tendo como objetivo retirar o problema das páginas dos jornais. 
Isto começou a ocorrer já no Governo Figueiredo, em que o Ministro Ludwig, mais por comodidade do que por convicção, cedeu desnecessariamente às demandas corporativistas para acabar com uma greve que se estendia por meses, destruindo as exigências de qualificação acadêmica para a carreira universitária e permitindo a efetivação de centenas de professores sem preparo adequado.

Há ainda um outro problema, que diz respeito às conseqüências da mobilização grevista para a vida interna das universidades. A generalização das assembléias como mecanismos de decisão alimenta um igualitarismo que é freqüentemente usado pelos professores mais jovens ou menos qualificados como um atalho para o acesso ao poder, sem passar pela formação acadêmica que faz parte das exigências normais de qualquer universidade de bom nível, em qualquer lugar do mundo. Ocorre, então, uma perversão da vida universitária, pois a competência científica e intelectual passa a ser irrelevante no processo de tomada de decisões que afetam o ensino e a pesquisa. Aceito esse igualitarismo, reitores e diretores comprometidos com suas bases, são incapazes de usar critérios acadêmicos para decidir sobre questões acadêmicas, e as questões sindicais passam a controlar todo o trabalho universitário.

\section{Como sair deste atoleiro?}

A única maneira de fazê-lo, a meu ver é recolocar a universidade onde ela sempre deveria estar: como uma instituição a serviço da sociedade, e não apenas dos seus professores e funcionários. As universidades que tiveram sucesso no País, como a Universidade de São Paulo, nunca perderam isto de vista; existem algumas outras universidades com vocações definidas, e até mesmo universidades particulares que têm sucesso realizando seu papel social de formar mão-deobra qualificada adequadamente.

O objetivo de uma política para o ensino superior é fazer com que as universidades realizem sua vocação e cumpram seu papel social.

A ausência de política, de um lado, desvirtua o movimento docente, exacerbando seu lado corporativo, mas, de outro, ela tem um significado que precisa ser denunciado, pois a ausência de políticas não deixa de ser uma política e, em muitos casos, das mais eficazes. Isto é o que está ocorrendo no País como um todo, em que a inércia e a apatia do Governo em muitas áreas é atribuída à falta de vontade política; enquanto isso, contudo, no mundo real, que é o da atividade 
econômica e dos negócios, as coisas estão se processando normalmente, às vezes com avanços significativos das correntes mais retrógradas. O que ocorre no Brasil é que raramente as políticas são explícitas, havendo um verdadeiro conluio para trabalhar com políticas implícitas menos transparentes e menos vulneráveis ao escrutínio público e à crítica.

Só para dar um exemplo fora da área de educação, tomemos o caso das mineradoras e serrarias na região amazônica, que vão avançando inexoravelmente, destruindo a floresta e as culturas indígenas, enquanto se processam discussões intermináveis sobre a politica de ocupação da Amazônia.

Na área de educação, o avanço da escola privada, com a facilitação na criação de escolas e a fixação generosa de anuidades está ocorrendo o tempo todo, enquanto se discute com o Ministério da Educação a indissóciabilidade do ensino e da pesquisa. Esta discussão acabou se transformando numa manobra diversionária, enquanto outras políticas são implementadas na prática.

A aparente ineficácia do Governo Federal não é fruto apenas do desinteresse ou da incompetência dos ministros nas suas áreas de atuação, mas é parte integrante de uma situação política que promove o livre jogo de interesses privatistas, no qual os mais instrumentados - que são os grupos econômicos - acabam levando a melhor.

Esta é a principal razão pela qual é indispensável a fixação de políticas, única maneira que o Poder Público tem de balizar legitimamente o terreno em que ocorrem as lutas de interesses.

Formular uma política significa, em primeiro lugar, estabelecer objetivos básicos e, em função deles, determinar prioridades. Para o ensino superior, esses objetivos e prioridades incluem:

- a diversificação do sistema;

- a democratização da gestão universitária, especialmente no sentido de garantir que as demandas da sociedade estejam sendo atendidas e que os recursos públicos estejam sendo utilizados de forma criteriosa;

- a promoção da melhoria da qualidade do ensino e do aumento da quantidade e da qualidade da produção científica, atra- 
vés de incentivos à pesquisa e do estabelecimento de uma carreira que premeie a competência e a dedicação;

- a descentralização do sistema.

A formulação de uma política significa também propor medidas concretas que permitam realizar os objetivos propostos.

A melhoria da qualidade passa por uma estruturação da carreira docente que promova a qualificação crescente dos professores e pesquisadores. A progressão na carreira - e a remuneração correspondente - deve ser resultado do mérito e da titulação, e não do tempo de serviço, como ocorre atualmente em universidades federais.

Nem todas as instituições de ensino superior podem - nem devem - ser idênticas. Elas precisam definir vocações locais, regionais, ou até nacionais, e devem escolher áreas onde possam atuar com sucesso dentro do contexto social em que estão inseridas. A diversificação é necessária, desejável e urgente, e cabe ao Ministério da Educação dar os primeiros passos nesse sentido.

É preciso reconhecer a legitimidade e a importância de iniciativas nessa direção e estimulá-las sempre que possível. Isso requer a alteração de procedimentos e critérios de credenciamento das instituições de ensino superior e a modificação do próprio Conselho $\mathrm{Fe}$ deral de Educação. A experiência inglesa poderia ser aproveitada no Brasil para rever radicalmente a nossa prática burocrática.

A democratização da universidade exige uma abertura maior dos Conselhos Curadores ou dos Conselhos Universitários a representantes da sociedade civil. A presença de representantes de sindicatos de trabalhadores e patronais é uma forma importante de abertura nesse sentido. Mas esses representantes estão freqüentemente distanciados da realidade universitária e sua contribuição é, por isso, muitas vezes limitada. A inclusão de representantes dos ex-alunos constituiria uma outra forma de abertura, pois permitiria a inclusão, nos órgãos decisórios, de lideranças políticas, artísticas, e profissionais, cuja familiaridade e interesse pela universidade estaria assegurada pela sua vivência na vida acadêmica. Teriam também uma visão crítica da formação que a universidade oferece em termos de sua própria experiência profissional. A representação das associações científicas poderia ser igualmente relevante, especialmente no sentido de assegurar uma avaliação competente da produção científica da universidade. 
Democratização significa também o controle do uso dos recursos públicos. Uma forma de fazê-lo é estabelecer algum vínculo, por mais tênue que seja, entre verbas e desempenho; atualmente esta vinculação não existe na prática e há uma verdadeira conspiração entre os burocratas do Ministério da Educação, que desejam conservar o poder de distribuir verbas de forma clientelística, e os reitores e associações de professores que temem uma vinculação do atendimento de suas reivindicações a exigências de desempenho. A ausência de avaliação é inaceitável porque obviamente a sociedade, através do Estado, sustenta a universidade para desempenhar um papel e tem o direito de verificar se este está sendo cumprido e se os recursos públicos estão sendo bem aplicados.

Além disso, o ensino superior, queiram ou não os docentes, é avaliado às vezes por critérios inadequados pelos técnicos do Ministério do Planejamento que alocam as verbas no orçamento público. $\mathrm{Pa}$ ra estes técnicos, universidades competem com verbas para ensino primário, transportes, saúde e infra-estrutura. Distorções ou generosidades ocasionais que beneficiam universidades, como tem ocorrido, não vão se manter indefinidamente. Num regime democrático sério e competente, a concessão de recursos adicionais deve estar vinculada à demonstração de que servirão efetivamente para garantir a ampliação do ensino e da pesquisa e a melhoria de sua qualidade.

É notório que a maioria dos ministérios como o Ministério de Ciência e Tecnologia e o de Educação não processam, por comodidade ou expediente político, as demandas que chegam a eles, mas simplesmente os encaminham para a SEPLAN. Dessa forma, as solicitações de verba ultrapassam de muito as disponibilidades do Tesouro. Sem a discussão de prioridades, cabe à SEPLAN apenas a redução global dos montantes, cortando igualmente o necessário e o supérfluo. Só para dar um exemplo, o déficit previsto para 1988 é de $100 \%$, ou seja, para uma receita de 2 trilhões de cruzados as despesas previstas são de 4 trilhões. Este é o problema que aflige agora o Ministério de Ciência e Tecnologia, que tem um orçamento de 1.2 triIhões, e pediu uma suplementação de 3 bilhões em julho de 1987.

A responsabilidade pelo uso de fundos públicos aumenta num regime democrático e isto fatalmente vai ocorrer no Brasil.

O desafio com que nos defrontamos é o de sermos capazes de desenvolver um sistema de ensino superior eficiente, de boa qualidade, que tenha credibilidade junto aos poderes públicos. Um sistema 
ineficiente pode ser mantido a custos reduzidos e não há porque canalizar recursos para instituições que não justifiquem investimentos elevados. Se não conseguirmos formar pessoal qualificado e não nos transformarmos em centros de produção científica e inovação tecnológica, essas funções acabarão sendo realizadas por algumas instituições de elite, públicas ou privadas, fora da área de atuação do Ministério da Educação. O sistema educacional, propriamente, se tornará muito semelhante ao de outros países da América Latina, onde universidades de massa atendem às pressões populares, as elites são formadas em outras instituições e a pesquisa se concentra em institutos desligados do ensino.

E por estas razões que um novo diálogo adulto e altivo deve se estabelecer entre o Ministério de Educação e as Universidades, diálogo este onde se acertem critérios para alocação de verbas com destinação transparente. E a falta desta transparência que cria a ilusão de que os recursos para a Educação são infinitos e que encoraja reivindicações às vezes estapafúrdias, como a de subsidiar integralmente refeições para os estudantes e funcionários. Estes subsídios, que montam a dezenas de milhões de cruzados, subtraem recursos para ensino e pesquisa. Apresentado o problema de maneira clara, acho difícil que os professores e até os alunos defendam estes subsídios em prejuízo de outras necessidades de interesse do ensino e da pesquisa.

As universidades deveriam apresentar ao Governo projetos concretos de desenvolvimento próprio que possam ser entendidos pela Sociedade e, recebendo os recursos necessários, devem apresentar os resultados concretos decorrentes da aplicação destes recursos. Não se trata de pedir simplesmente mais verbas - o que todos os órgãos governamentais fazem - mas recursos para fins bem explicitados, mesmo que inteiramente dedicados a assuntos de interesse acadêmico.

Por sua vez, o Ministério deveria se distanciar da alocação direta de verbas, estabelecendo uma Comissão mais ampla onde tenham assento representantes credenciados da sociedade brasileira.

Ao Ministério deveria caber um papel regulador e de tomador de contas, abandonando a tendência estado-novista de um controle direto de todo o funcionamento das Universidades.

Finalmente, o Ministério deveria criar um seminário especial para reitores, a exemplo do que ocorre na Europa, onde o Conselho de Reitores das Universidades do Mercado Comum Europeu prepara os reitores - após sua escolha - para o exercício da função. Com a 
efervescência política atual nas Universidades, professores que atingem o cargo de Reitor estão freqüentemente despreparados para as atividades administrativas e financeiras da missão que os espera.

Mais ainda, como reitores não são cargos permanentes e mudam a cada 4 anos, cabe criar um grupo de funcionários - estes sim permanentes - que assumam os encargos administrativos das universidades e que os exerçam com competência. As universidades devem funcionar como os regimes parlamentares da França, Inglaterra, e muitos outros países onde os ministros mudam com freqüência, mas a administração de todo o dia é conduzida de forma apolítica e eficiente por um grupo seleto de secretários-gerais e outros funcionários.

Um conjunto de medidas como essa pode imprimir uma nova direção às mudanças que hoje ocorrem no sistema universitário de forma caótica, garantindo a utilização mais criteriosa dos recursos públicos, a autonomia das universidades, o controle público do sistema e promovendo aquilo que todos nós desejamos: universidades de alto nivel, capazes de criar e transmitir um conhecimento novo que seja relevante para a Nação.

\section{FICHA CATALOGRÁFICA}

GOLDEMBERG, J. Uma política para a Educação Superior. Revista da Universidade de São Paulo. São Paulo, (6): 87-97, jul./set. 1987. 